\title{
Work-integrated learning within the reading literacy component of foundation phase teacher preparation programmes
}

\begin{tabular}{|c|c|}
\hline \multicolumn{2}{|c|}{$\begin{array}{l}\text { Authors: } \\
\text { Zelda Barends }{ }^{1} \\
\text { Carisma } \mathrm{Nel}^{2}\end{array}$} \\
\hline \multicolumn{2}{|c|}{$\begin{array}{l}\text { Affiliations: } \\
{ }^{1} \text { Foundation Phase and } \\
\text { Early Childhood Education } \\
\text { Department, Faculty of } \\
\text { Education and Social } \\
\text { Sciences, Cape Peninsula } \\
\text { University of Technology, } \\
\text { South Africa }\end{array}$} \\
\hline \multicolumn{2}{|c|}{$\begin{array}{l}{ }^{2} \text { School for Human and } \\
\text { Social Sciences Education, } \\
\text { North-West University, } \\
\text { South Africa }\end{array}$} \\
\hline \multicolumn{2}{|c|}{$\begin{array}{l}\text { Corresponding author: } \\
\text { Zelda Barends, } \\
\text { barendsz@cput.ac.za }\end{array}$} \\
\hline \multicolumn{2}{|c|}{$\begin{array}{l}\text { Dates: } \\
\text { Received: } 17 \text { Apr. } 2016 \\
\text { Accepted: } 11 \text { Nov. } 2016 \\
\text { Published: } 23 \text { Mar. } 2017\end{array}$} \\
\hline \multicolumn{2}{|c|}{$\begin{array}{l}\text { How to cite this article: } \\
\text { Barends, Z. \& Nel, C., 2017, } \\
\text { 'Work-integrated learning } \\
\text { within the reading literacy } \\
\text { component of foundation } \\
\text { phase teacher preparation } \\
\text { programmes', South African } \\
\text { Journal of Childhood } \\
\text { Education } 7(1) \text {, a435. https:// } \\
\text { doi.org/10.4102/sajce. } \\
\text { v7i1.435 }\end{array}$} \\
\hline \multicolumn{2}{|c|}{$\begin{array}{l}\text { Copyright: } \\
\text { (C) 2017. The Authors } \\
\text { Licensee: AOSIS. This } \\
\text { is licensed under the } \\
\text { Creative Commons } \\
\text { Attribution License. }\end{array}$} \\
\hline \multicolumn{2}{|l|}{ Read online: } \\
\hline 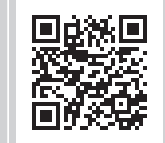 & $\begin{array}{l}\text { Scan this QR } \\
\text { code with your } \\
\text { smart phone or } \\
\text { mobile device } \\
\text { to read online. }\end{array}$ \\
\hline
\end{tabular}

Research confirms that the quality of instruction learners experience day-to-day matters for learner achievement more than any other school-based factor. Yet teachers beginning their careers across a range of contexts routinely report that they are unprepared to enact highquality instruction on day one. Thus, the quality and content of pre-service teacher preparation programmes features prominently in learner success. Research reveals that purposeful coordination between teacher preparation programmes and the school districts with which they partner, tightly aligned curricula and field experiences, and extensive clinical practice can improve teacher preparedness (Darling-Hammond \& Bransford 2007). The purpose of this article was to conduct a survey among selected universities offering Bachelor of Education (BEd) foundation phase programmes, to determine the role of work-integrated learning (WIL) in facilitating the preparedness of pre-service teachers to teach reading literacy. The results indicate that there is an urgent need to focus on the following aspects as they relate to WIL and its integration with reading literacy-specific content: the purpose of WIL as it relates to reading literacy; the degree of integration between coursework, specifically reading literacy and practice-based experiences (i.e. practice teaching); the relationship and partnerships between university lecturers and teachers and district officials; and the training of teachers to support the pre-service teachers.

\section{Introduction}

What do you want your students to achieve during practice teaching or work-integrated learning as you now call it?

Do you really think your students learn how to teach reading or maths during practice teaching?

These are some of the questions asked by a foundation phase head of department that made us want to look critically at how universities were approaching work-integrated learning (WIL) in their Bachelor of Education (BEd) foundation phase programmes.

There has been an enormous amount of attention on teacher quality and preparation (cf. Department of Basic Education [DBE] \& Department of Higher Education and Training [DHET] 2011; Taylor \& Mayet 2015). The general conclusion is that for there to be a change in primary school learner achievement, there must be a change in those who teach the learners. An effort to increase teachers' proficiency and efficacy is a critical component in making necessary changes to the South African education system. The focus is now clearly on the teacher preparation programmes that prepare those teachers (DBE 2015; DBE \& DHET 2011).

The Council on Higher Education (CHE) conducted a National Review of Academic and Professional Programmes in Education between 2005 and 2007, and published a report in 2010. The report pointed to the need to focus on programme practices at universities in order to improve the quality of initial teacher education (i.e., the nature of ITE programmes, their content, depth and breadth, the orientations that underpin them, their practice-theory balance, the wide variation between programmes and the lack of collaboration between institutions).

A recent research study into initial teacher education led by JET Education Services and supported by the Department of Higher Education and Training and the Department of Basic Education reported findings that raise serious questions about initial teacher education for primary (intermediate phase) teachers. The research study focused on aspects of BEd programmes that were focused on developing the ability of intermediate phase initial teacher education students to 
teach literacy and mathematics. The research showed that the content of modules and hence of programmes varies widely among universities. Teaching practice is the area with the greatest variation in coherence and in terms of quantity and quality. The programmes seem to lack a strong underlying logic and coherence (reinforcing the findings of the CHE review) (cf. Taylor \& Mayet 2015).

Similarly, a survey conducted by Zimmerman, Howie and Long (2008:58) aimed to describe how pre-service teachers are being trained to teach literacy to South African foundation phase learners. The researchers found that there is a wide variation in both the programme goals and the design of the programmes at various institutions within the country. The content for these literacy programmes was well considered as each module and study unit served a specific goal for teacher education that was in line with the national curriculum and international trends. However, time limitations, resource inadequacies and lack of optimal opportunities for student teachers' practical exposure impeded the achievement of the programme goals.

The primary outcome of the Integrated Strategic Plan for Teacher Education and Development in South Africa 20112025 (DBE \& DHET 2011) is to improve the quality of teacher education and development in order to improve the quality of teachers and teaching. In the context of this plan, the universities that provide teacher education programmes, supported by the DHET, have the responsibility for ensuring that:

- their programmes are accessible to teachers and aspirant teachers

- the programmes being offered are responsive to national, provincial and individual teacher priorities and needs

- the programmes are of high quality and lead to meaningful development for teachers.

In particular, universities will need to implement innovative mechanisms to strengthen the WIL component of teacher education programmes, for example, through the effective use of Professional Practice Schools (PPSs) and Teaching Schools (TSs). In addition, the Plan identifies, among others, essential requirements for it to succeed: enhanced collaboration among role-players, a coordinated national system for teacher education and development, adequate time for quality teacher education and development, and sufficient funding for quality teacher education and development.

The US National Research Council report (2010:180) cited clinical experience as one of three aspects of teacher preparation likely to 'have the highest potential for effects on outcomes for students'. Research studies have shown the benefits of teacher preparation that is directly linked to practice (Boyd et al. 2008). Three critical features of such preparation are (1) right integration among courses, and between course work and clinical work in schools; (2) extensive and intensively supervised and mentored clinical work integrated with course work; and (3) close, proactive relationships with schools that serve diverse learners effectively and develop and model good teaching (DarlingHammond 2006). Research conducted in South Africa clearly indicates problems in teacher preparation programmes with regard to the above-mentioned aspects (cf. Gravett et al. 2015; Heeralal 2014; Rusznyak \& Bertram 2015; Taylor 2015).

The purpose of this paper is to conduct a survey among selected universities offering BEd Foundation Phase programmes, to determine the role of WIL in facilitating the preparedness of pre-service teachers to teach reading literacy.

\section{WIL in teacher preparation programmes: The enactment of the reading knowledge base}

\section{WIL: A definition}

According to Cooper, Orrell and Bowden (2010:37), WIL is an umbrella concept encompassing a variety of terms used in professional, vocational, liberal arts and science education. This metaphor of the umbrella concept is extended by the CHE (2011:4), which states that the term 'WIL' is also used to describe curricular, pedagogic and assessment practices across a range of academic disciplines that integrate formal learning and workplace concerns. These curricular, pedagogic and assessment practices aid the integration of theory and practice in student learning which is what the implementation of WIL approaches aims to achieve (CHE 2011:4). Put simply, WIL is primarily intended to enhance student learning by integrating formal learning (theory) and workplace learning (practice).

Similarly, WIL can be described as an approach to career-focussed education that includes classroom-based and workplace-based forms of learning that are appropriate for the professional qualification. However, what distinguishes WIL from ideas of learning-for-work is that it emphasises the integrative aspects of learning to work (practice). WIL could thus be described as an educational approach that aligns academic and workplace practices for the mutual benefit of students and workplaces (CHE 2011:4). This is supported by Cooper et al. (2010:41) who purport that WIL involves student engagement in experiential and situated learning because an intentional aspect of the above-mentioned definition which can be highlighted is that learning is situated within the act of working.

\section{Conceptual framework}

The purpose of a conceptual framework is to learn from the experience and expertise of others as you develop your own knowledge and perspectives, as it allows you to make reasoned, defensible choices about how the research will be explored (Ravitch \& Riggan 2012:14). Moreover, a conceptual framework is constructed as it incorporates pieces of information obtained through research; therefore, it is a framework which is built by incorporating relevant theories 
and research conducted about the phenomena studied as this could be key sources to understand what is going on with the phenomena being studied (Maxwell 2005:41).

Cooper et al. (2010:37) state that WIL is characterised by seven key dimensions: purpose, context, nature of the integration, curriculum issues, learning, partnerships between the university and the workplace or community, and the support provided to the student and the workplace. The value of WIL is that it takes the strengths of the theoretical orientations of academic education and blends these with the rich, tacit practice knowledge of workplaces and communities. This integration is achieved through focusing on the seven key dimensions when planning and implementing WIL. These dimensions as proposed by Cooper et al. (2010:39-42) will form the conceptual framework for WIL in this study. Cooper et al. (2010:39) proposed that successful implementation of any WIL model needs to include all seven dimensions of the framework. Cantalini-Williams et al. (2014:5) state that the seven dimensions are not deemed to be hierarchical or mutually exclusive.

\section{Purpose}

According to the Policy on the Minimum Requirements for Teacher Education Qualifications (DHET 2015:13), WIL, learning-in-practice, 'must be structured, supervised, integrated into the learning programme, spread across the learning programme and it must be formally assessed'. Traditional practice teaching is out of date and insufficient. What is needed is a new vision for WIL that will help preservice teachers prepare for an increasingly diverse learner population and that leads to better outcomes for all learners. It is not merely a matter of doing more; it involves rethinking every aspect of WIL.

Cooper et al. (2010:39) state that having a clear purpose for WIL goes beyond simply integrating theory and practice. A clear purpose for WIL will clarify goals, and articulate expectations and intended outcomes for all the stakeholders involved in WIL, namely, the students, the workplace, the university, the school district, and the community. This will ensure that strong partnerships develop in suitable contexts that facilitate integrated, supported student learning. In addition, defining the purpose of WIL experiences for students will also serve as a guide as to which WIL model to use. Cantalini-Williams et al. (2014:23) state that one needs to take cognisance of many considerations in terms of the purpose dimension. Student teachers' perceptions of teaching beyond the traditional classroom need to be broadened and are needed as emphasis is placed on WIL in diverse contexts. Because of the fact that there is a need to develop and articulate intended outcomes for all the stakeholders involved in WIL, they (the stakeholders) need to be involved and give input in this activity of developing and articulating outcomes as well as clarifying their role within WIL. This working relationship will have to be an ongoing and interactive occurrence among stakeholders where they co-construct the WIL component together (Darling-Hammond, Bullmaster \&
Cobb 1995:90). In addition, Cantalini-Williams et al. (2014:23) purport that if purposeful outcomes are to be implemented and realised, preparatory activities and appropriate supporting materials need to be in place before and during as well as upon the completion of a practicum.

This has major implications for the preparation of reading literacy teachers. The stakeholders involved in reading literacy teacher preparation would include classroom (mentor) teachers, curriculum advisors (districts) and university lecturers. All these stakeholders would need to get together to form a community of practice where they could determine a clear purpose for WIL. A clear purpose for WIL, specifically envisioned for reading literacy, should address the diverse reading literacy needs of learners in the foundation phase. Once the purpose has been defined with all the stakeholders involved, they will have a clearer idea of their role within WIL and will be able to contribute to the students learning.

\section{Context}

Contexts or the workplace are important for practice learning for professions as learning is achieved through work (Cooper et al. 2010:39). This is facilitated through various strategies such as guided learning, mentoring and coaching as learners are immersed in a community of practice where they move from the periphery to full participation (Lave \& Wenger 1991:34-35). Cantalini-Williams et al. (2014:23) identify the context dimension as the diverse workplace settings that allow for the direct application of teaching and pedagogical skills'. Moreover, by immersing student teachers in authentically diverse South African contexts, teacher education becomes more realistic, providing a stronger link between theory and practice (Robinson 2015:12).

The context for teaching today is vastly different from what it was 50 years ago. Today's teachers will have to educate all learners, including those from increasingly diverse economic, racial, linguistic and academic backgrounds, to the same high learning outcomes. In a review of the literature on working with diverse learners, Hollins and Torres-Guzman (2005) found that many researchers have suggested that teacher candidates would greatly benefit from early and intensive field experiences in diverse settings. The life experiences of the learners and community surrounding high-need sites are often quite different from those of most teacher candidates. Just driving through the community to reach one's field placement site can present pre-service teachers with different social, political and economic realities affecting their learners, families and education in general.

Exposure to various contexts is vital in reading literacy teacher preparation. Students need to be exposed to various contexts so that they can apply their content knowledge and also develop PCK. The exposure to diverse contexts such as urban and rural schools, as well as schools from various quintiles, also grants students the opportunity to be confronted with realistic or real-world situations where they 
will be able to connect theory to practice. In addition, students need to become accustomed to the professional ethos of the school as site of working.

\section{Integration}

Within WIL, integration refers to the process of putting together formal learning and productive work (Cooper et al. 2010:40). Put simply, it refers to connecting theory and practice as it involves the application of theory with realworld problem solving, abstract thinking, practical actions and discipline-specific skills or PCK as defined by Shulman (1987:7) (Cantalini-Williams et al. 2014:5; Cooper et al. 2010:40). Darling-Hammond et al. (1995) illustrate this by stating that:

effective teaching is context based and must be adapted to individual students, successful teacher preparation must involve not only a foundation of theoretical knowledge but also a rich array of classroom experiences that help teacher candidates integrate their formal knowledge of teaching and learning with the knowledge of adaptive practice that can be gained only by working with the guidance of experienced teachers. (p. 95)

It is important to note that integration is not simply an action but rather a learning process which is encouraged in student learning in the workplace and the university through dialogue, reflection, tutorials and assessable work. This should require of students to put knowledge into action and develop the ability to act knowledgeably and responsibly in the workplace context (Cooper et al. 2010:40). However, this can only happen if a curriculum is aligned. Thus, work done in lectures should be aligned with practice. Lectures should include reflection on case studies and the analysis of teachers' work.

Reading is fundamental to many life activities and is perhaps the most essential skill children learn in school. Unfortunately, children who do not learn to read well during the foundation phase typically struggle with reading in the intermediate phase and beyond. The Annual National Assessments conducted in 2014 indicated that Grade 3 learners achieved $56 \%$ for Home Language, Grade 4 learners 57\% and Grade 9 learners 48\% (DBE 2013). Foundation phase teachers, not reading specialists, are solely responsible for the reading instruction of all children and, ultimately, for their reading achievement (cf. Valencia \& Buly 2004). However, many teachers are not prepared to effectively teach reading (Cunningham et al. 2004; Moats \& Foorman 2003; Taylor \& Mayet 2015).

In light of this, there is a need to look at ways in which preservice teachers are prepared to teach reading. The challenge in preparing pre-service teachers to teach reading is that they must be able to link new knowledge learnt through coursework to instructional practices through the practicum or internships. Reading teacher preparation that is field based and that emphasises practicum experiences seems to have the most positive effects, specifically supervised, mentored, relevant, field-based or clinical experience in which pre-service teachers receive constant support, guidance and feedback (Hoffman, Roller \& National Commission on Excellence in Elementary Teacher Preparation for Reading Instruction 2001). More practicum experiences provided for pre-service teachers help them to apply what they learn in coursework; most importantly, the support they receive during practicum experiences helps them make sense of what they are learning (Andrew 1990). Expertise to teach reading matters more than curriculum materials, pedagogical approaches and reading programmes (Allington 2002), and it can be developed through experiences, careful deliberation and reflection on practice, usually through supervision by knowledgeable mentors (Cochran-Smith 2000) using evidence-based reading research practices. Authentic apprenticeships that allow teacher candidates to openly discuss their literacy practices through collaborative problem solving are powerful opportunities to enhance learning (Risko et al. 2008). Within the construct of teacher training, the concept of critical self-reflection has emerged as a legitimate strategy for improving and transforming one's practice (Dufour 2004). Research (Darling-Hammond 2006; Dufour 2004) affirms that structured opportunities for colleagues (i.e. university faculty and expert classroom teacher-mentors) to engage in collaboration yield increased pre-service teacher knowledge and improved pedagogical practice.

\section{Curriculum}

According to Cooper et al. (2010:40), learning in the workplace should be included in the curriculum. Curriculum as a dimension of WIL acknowledges that declarative knowledge, which is the information passed on in books and lectures about theory, and functional knowledge, which is the application of declarative knowledge in real-world situations, are integrated into experiences. Put simply, declarative knowledge (theory acquired in coursework, namely, the what) and the functional knowledge (workplace practice or the how) are integrated into the WIL experience (CantaliniWilliams et al. 2014:5; Cooper et al. 2010:40). This will lead to major implications for implementation in that it involves making sure that learning in the workplace is embedded throughout coursework at universities as well as the workbased curriculum. However, Cooper et al. (2010:40-41) suggest that the curriculum should be constructively aligned. This refers to the practice of defining intended learning outcomes, choosing teaching and learning activities that lead to achieving these outcomes, and assessing students to measure whether the outcomes set have been mastered and to see how well they matched what was intended, and a final mark should then be given (CHE 2011:13). The constructive alignment of the curriculum provides a structure for designing WIL as curriculum alignment in WIL aims to ensure that outcomes, pedagogy and assessment are matched (CHE 2011:13).

Furthermore, Cantalini-Williams et al. (2014:24) emphasise that teacher preparation programme coursework should address the importance associated with the practicum 
experience and include content on topics such as effective strategies for mentoring as mandatory elements of the core curriculum. Practicum experiences should also be aligned with the curriculum of the teacher education programme and the interests and expertise of the participants. In addition, both the theoretical knowledge (what) and practical knowledge (how) need to be included in the curriculum. Teacher preparation programmes also need to ensure that assessment practices are aligned with the learning outcomes set for the practicum component. Because of the fact that the workplace learning can be so diverse, students need to consider and understand the culture of the practicum setting. In order to achieve this, the curriculum of teacher preparation programmes should include courses intended to address the specific outcomes and culture of the practicum setting to be experienced. In order to achieve this, stakeholders involved in WIL can collaboratively plan curricula; even though this would require major compromises in content by the stakeholders involved, the end product will increase coherence in the curriculum and address the theory and practice divide sufficiently.

\section{Learning}

According to Cooper et al. (2010:41), WIL involves student engagement in experimental and situated learning, which should be guided by clearly explained learning intentions and expected learning outcomes. This is because learning is always a work in progress and has a developmental component (Cooper et al. 2010:63). This is illustrated clearly when Cooper et al. (2010:41) state that within WIL students participate in a spiral learning process where theory and practice are conceptualised and reconceptualised with each spiral deepening the students' understanding.

In order to understand this spiral, we need to look at how knowledge is built through WIL. Knowledge is acquired at universities through traditional academic lectures, but it does not transfer to practice in the workplace in a straightforward manner. This is because there is a distinct difference in the way knowledge is organised in university courses. In academic programmes, knowledge is 'packaged' in the form of separate academic subjects which contrasts to the way that knowledge is acquired in practice. In practice, knowledge is often tacit and is acquired in a more social way and in a situated context (CHE 2011:11). In the field of Education, there are some basic skills that transfer well to the workplace, but the success thereof is limited to routine practices. However, when the workplace presents circumstances where complex and discretionary judgements are required, a more complex form of knowledge is needed, which is usually acquired in an academic lecture (theory). Inherently, this is regarded as a scientific form of knowledge. The CHE (2011:11) states that scientific knowledge (theory) should be acquired for what it is because if it is learnt in a practical context, it gets tied to that context and the transfer capacity is lost. In addition, theory provides the knowledge base for posing and solving problems in the world of professional practice.
This highlights a difficulty students experience because this knowledge is obtained from their university academic courses, and they often fail to understand the relevance of disciplinary knowledge, and experience difficulties in transferring what they learned in the lectures to the workplace (CHE 2011:11). Thus, in order to deal with this complex issue, a transformative process is needed where students will have to change their understanding and interpretation of theory, personal perspective, beliefs, values and practice. In other words, this transformative process helps students to comprehend what they are doing and learning, interpret theory, practice it and develop personal dispositions (Cooper et al. 2010:41). A way to achieve this is through co-teaching. Mentor teachers and students can co-teach, and through coteaching both the mentor teacher and student assume responsibility for the planning and enacting of the teaching. Thus, an opportunity for ongoing problem solving and interaction about the learning is created and takes place.

The use of mentoring has nowadays become a predominant practice for the practicum placement component of preservice teacher preparation programmes. Classroom-based teachers are relied upon to mentor pre-service teachers in practical aspects of learning to teach. Within the context of a mentoring scenario, the pre-service teacher's needs are catered for and learning opportunities are negotiated between the mentor teacher and the pre-service teacher. The classroom-based teacher who agrees to mentor a pre-service teacher needs to nurture, advise, guide, encourage and facilitate authentic learning experiences for developmental growth (Ambrosetti \& Dekkers 2010). Despite the important role that mentor teachers play in the development of the future generation of teachers, research has demonstrated that few teachers receive training or preparation for mentoring (Hall et al. 2008). In many instances, it is assumed that if a teacher is considered to be an effective practitioner, he or she can pass on his or her skills and knowledge to another as a mentor. Mentoring is not a natural ability that people inherently have; therefore, an effective teacher may not necessarily make an effective mentor. Nevertheless, Hennissen et al. (2011) have shown that mentoring skills can be learnt and developed over time.

\section{Partnerships}

Turning teacher preparation programmes upside down by putting clinical practice at the centre cannot be accomplished by teacher preparation programmes working alone. Universities, school districts and schools need to accept that their common goal of preparing effective teachers (i.e. pre-service, induction and continuous development) for improved learner achievement cannot be achieved without each other's full participation (Robinson 2015).

\section{Clifford and Miller (2007) define partnership as follows:}

A K-20 partnership is an organization (i.e., a social entity in which people routinely engage together in tasks) that is formed through a formalized agreement among partners, comprising at least one actively-engaged college/university and one actively-engaged 
$\mathrm{K}-12$ school district and is intended to accomplish mutual benefits that the partners, alone, could not accomplish. (p. 11)

They go on to elaborate on four attributes. In order to be a partner organisation, goals are shared, routines are established which persist over time, and thorough paths of interpersonal relationships and tasks are routinely completed. Next, they require partnerships to represent at least two different organizations, not just individuals from different organizations. Partnerships call for formalised arrangements. The partner organizations have to commit to support the work that is undertaken by individuals within the organizations. In the absence of such formal commitment, individuals from different organizations would be viewed as having working relationships. The third element of their working definition underscores that there are mutual, not necessarily equal, benefits, which can include knowledge advancement, improved reputation, the provision of services (often unavailable otherwise) and organizational or professional learning and change. The fourth and final element of their definition focuses on interdependence among partners. Partners need one another to achieve ends they could not, or at least could not easily, achieve by themselves. The basic model of university coursework plus practice teaching rounds in its various manifestations with informal arrangements with schools has been found wanting (Hattie 2009).

WIL builds links between workplace knowledge and the academic curriculum. It also helps students to transfer academic knowledge to workplaces. Thus, for this reason, Cooper et al. (2010:42) accentuate that WIL is not possible without the establishment of partnerships between the work industry (i.e. school districts and schools) and universities. The effectiveness of WIL depends, to a major extent, on the commitment of both academic and professional partners. For too long educational institutions and practice communities have been merely interested, disconnected observers of each other (Cooper et al. 2010:34). For reciprocal partnerships to be established, there needs to be synergy between partners so that if there is a major shift or change of direction or values in one, it will impact the other (Cooper et al. 2010:34). Typical partners for reading literacy teacher preparation would be the subject lecturer from the university, the district subject advisor for literacy, the classroom teacher and the student enrolled within the reading literacy teacher preparation programme, thus forming a community of practice.

Cooper et al. (2010:34-35) state that these principles have relevance for higher education for the formation of WIL partnerships as it is now time for universities to recognise that their WIL programmes provide mechanisms for establishing authentic, multidimensional relationships with their local communities and related industries, and to value them because of this potential, not merely as a means of producing work-ready graduates. Furthermore, Cooper et al. (2010:4) note that the partnerships between higher education institutions and work or community organisations are often based on goodwill alone. The new interest in WIL is provoking universities to change their systems to find ways to engage in programmes and partnerships that are mutually beneficial.

\section{Support}

Because of the fact that there are a number of partners involved in WIL, support is vital throughout the programme (Cooper et al. 2010:42). Cooper et al. (2010:42) state that students and workplaces require support before, during and after any WIL programme. This is because besides WIL being challenging, creating anxiety and uncertainty, students also come to higher education with diverse and unique experiences. Therefore, they need support in knowing how to approach organisations and present themselves to employers, as well as knowing what to expect and how learning takes place. Moreover, WIL is dependent on the partners involved; therefore, these partners involved in reading literacy teacher preparation should be trained on various aspects such as co-teaching, mentoring and the assessment of students engaged in WIL. Furthermore, Cantalini-Williams et al. (2014:6) state that support should be ongoing throughout the WIL programme as it accounts for and accommodates these diverse needs and includes the practical, administrative, educational and emotional components.

\section{Research methodology Research design}

In this study, a one-shot cross-sectional survey design was used to determine how selected universities, within their BEd foundation phase programmes, viewed the role of WIL in facilitating the preparedness of pre-service teachers to teach reading literacy. Cross-sectional surveys involve description and inferences from responses collected at one point in time (Mertens 1998). The design is descriptive in purpose because we want to indicate how universities are approaching the WIL component of their programmes as it relates to reading literacy, specifically. The BEd programme was therefore the unit of analysis and not individuals or the universities.

\section{Participants}

Due to ethical reasons the data source cannot be disclosed to protect the identity of the research participants, their institutions as well as their opinions.

Purposive sampling refers to a series of strategic choices about with whom, where and how a researcher conducts his or her research. This implies that the researcher's sample must be tied to the objective of the study (Palys 2008:697); put simply, the participants had to be knowledgeable in terms of how WIL is integrated with the reading literacy component of the teacher preparation programmes. The participants included in this study were lecturers working within the reading literacy component of teacher preparation programmes of the universities in South Africa $(n=14)$. These 
universities were involved in the European Union-funded Foundation Phase Project on Teacher Preparation Programmes. Approval for the project was given by the DHET. Furthermore, two School Management Teams (SMTs) (which included Heads of Departments (HOD) of the Foundation Phase) within the Blue District ${ }^{1}$ of the North West Province as well as the Green District of the Western Cape were randomly selected $(n=5)$ to participate in this study as students are typically placed within these schools for the WIL component of their course.

\section{Data collection methods}

The data collection methods chosen for this research provide rich data specifically focused on the research questions. Data collection methods included semi-structured interviews, focus group interviews and document analysis.

\section{Semi-structured interviews}

Individual, semi-structured interviews were used to generate perspectives and experiences on WIL with the lecturers from the various universities. According to Greef (2011:342), the interview is a social relationship designed to exchange information between the participant and the researcher. In addition, Merriam (2009:88) informs us that interviews are necessary when behaviour cannot be observed. Interviews elicit data that are not evident from documents. Interviews provide access to multiple perspectives. An interview protocol was designed for the participants.

\section{Focus group interviews}

Focus group interviews were also conducted with colleagues from the universities as well as the SMTs of the randomly selected schools to gain knowledge of and an understanding into their lived experiences of WIL. According to Nieuwenhuis (2007:90), the focus group interview strategy is based on the assumption that group interaction will be productive in widening the range of responses, and activating forgotten details of experiences.

\section{Documents}

According to Glesne (1999:58), 'Documents corroborate your interviews and thus make your findings more trustworthy. Beyond corroboration, they may raise questions about your hunches and thereby shape new directions for observations and interviews'. Various documents (i.e. syllabi, course outlines, course handouts and evaluation tools) were analysed.

\section{Methods of analysis}

Content analysis was used to arrive at the categories emanating from the data in light of the research questions. According to Grbich (2007:112), content analysis is a systematic coding and categorising approach which can be used to explore large amounts of textual information in order to ascertain the trends and patterns.

\section{Results}

The results are presented according to the themes which emanated from the analysis of the data.

\section{The purpose of work-integrated learning as it relates to reading literacy}

Purpose is a dimension which is highlighted in the conceptual framework of this study. The purpose and objectives of various role players as well as the context of WIL are highlighted in box 1 and 2.

\section{An interview participant indicated:}

\begin{abstract}
...[W]e have two Teaching Experiences per year, normally around three weeks each. It depends on the school calendar, school holidays, sometimes it's one day less but generally it's a 15 day teaching block. We have had discussions around the first year programme and what the structure does look like. The questions we're asking ourselves is, should first year BEd. Foundation Phase teacher educators be teaching? Should they not be teaching? Should they be supervised or not? And that's a question I don't think we've actually answered, but a question we looking to kind of debate around. In first year generally the first three weeks they are in a Foundation Phase setting - grade 1 , grade 2 , grade 3 - where they generally have an intensive observation task to get familiar with the programme, the daily routine, teacher practice, communicating with children, school surroundings, and culture of the school. The second teaching prac they spend two weeks in a foundation phase classroom and a compulsory one week in a grade $\mathrm{R}$ classroom because of government's move towards making it universal.
\end{abstract}

It appears as if the aims and objectives like the structure and format of WIL differ across institutions. Some institutions allow first year student teachers to teach and some do not; the focus is on observations and limited exposure. The documents do, however, refer to tasks such as the extracurricular activities and lesson observations, but guidance about why it should be done and how it is of value to the student teachers is either absent or kept to the minimum. Furthermore, there is no specific reference made to reading literacy within the purpose for WIL among the institutions. The extracts presented here also indicate that no critical reflection is demanded from the student as students simply have to 'be exposed to' various aspects of teaching.

Box 1: An extract from a university indicating its outcomes or objectives for WIL. The idea of this course is to prepare you to act with self-confidence in all teaching situations. The course will also assist you in discovering your strong and weak points. In this way you will enhance and develop your teaching practice.

Box 2: An extract from another university.
1. AIMS OF PRACTICE TEACHING
The aims of practice teaching are that students will:
1.1 Observe the work procedures, teaching methods and techniques, general classroom organisation and disciplinary methods employed by the mentor;
1.2 Be exposed to a variety of organisational and administrative aspects of education;
1.3 Be exposed to the extra-curricular activities of a school;
1.4 Get limited exposure to teaching, provided that they are guided by a teacher in the preparation and presentation of lessons. 


\section{Degree of integration between coursework, specifically reading literacy and practice-based experiences (i.e. practice teaching)}

The integration of knowledge is a key dimension of WIL; this is usually indicated by how students have to apply their knowledge. This also highlights the dimension of learning and the curriculum as these two dimensions allow for knowledge application and integration. The following extracts illustrate how students are expected to apply their knowledge as well as how they integrate their knowledge of theory and practice. These extracts relate to the dimensions of integration, curriculum and learning which refer to the process of connecting formal learning and productive work.

Many interview responses raised similar answers like²:

'There is no structured syllabus, only 1 credit is allocated for WIL. What is currently being done in the programme depends on the practice teaching programme leader. Currently there is no alignment between the course content and teaching practice. Students are only required to present lessons and there is no progression over the four years. The students are introduced to professional competencies in the course, one week at the beginning of the first year students are orientated around discipline, how to dress, where to sit in the staffroom. There is not much emphasis on ethics.'

Another participant indicated:

'We find that that is most helpful for them to go with a specific purpose, like with the allocation of assignments. So, if I work with challenges or barriers to learning, they need to do a case study on the school, on a specific learner and then it becomes a collective discussion around that, yes. So they do go in with specific assignments which then also serve as part of the purpose.

\section{Another participant indicated:}

'There is a lack of alignment between the reality of classroom teaching as the students don't know how to manage the daily routine in the classroom in terms of literacy content, maths and life skills. They simply cannot plan time wise. They are very good at planning a single standalone lessons for evaluation purposes, these lessons are also written out according to the university guidelines. Students cannot plan complete twoweekly schedules according to CAPS. It seems as if their knowledge is compartmentalised they don't see the bigger picture, so no it's not sufficient as students are not developing into the teachers we need.'

Another response includes:

'Their disciplinary knowledge is not up to standard especially the problems with identifying where/with what learners have problems. They can't implement specific interventions; they rely only on CAPS and move through it systematically. Students also don't know how to integrate assessment with instructional decision.'

2.Because of space restrictions, participant responses were filtered and only those responses which clearly illustrate the argument are presented.
Another participant indicated:

'Well, the lesson plan format that they are given makes provision for things like how does the lesson articulate with ones done before, where is it taking you, what research have you done, what are the resources and how are the resources integrated, what is the introduction and why is this the introduction, what is the conclusion and why is this the conclusion? Also, in what way do you assess and why, what is the content of the lesson, you know. So it's basically that and reflects on the critical incident during the teaching of this particular lesson. I think that is more or less what we do.'

Appendices A and B are two extracts from a university giving specific guidelines regarding observations and the assessment of students lessons.

The results clearly indicate that the development of the WIL curriculum and the learning taking place in the schools, by the pre-service teachers, is a one-sided affair. The university provides most of the input in terms of what they want and how it should be assessed or what observations should be made. There is not integrated input from either district level or from teachers in the school. This seems to indicate a lack of insight into exactly what is needed in schools and what core problem areas are. It is also clear that the WIL curriculum is not integrated to any significant degree with the reading literacy content covered in coursework at the universities. However, the use of the teaching school provides far more opportunities for coherence in terms of content.

\section{The relationship and partnerships between university lecturers and teachers and district officials}

There are various role players involved in WIL. The following extracts indicate the roles and relationship of the various role players. These extracts allude to the aspect of established partnerships which is a dimension of the conceptual framework.

\section{An interview participant indicated:}

'We have weekly teaching, where our students are placed in classrooms to teach lessons planned and prepared in conjunction with their lecturer on campus. The teachers of the classrooms in which they are based communicate the topics to the lecturer and the lecturer has to help the student prepare for their weekly teaching. Weekly teaching is for our first, second and third year students. Our students also engage in practice teaching twice a year which take place in April and July. This is from first to fourth year students. In this time students spend a minimum of 2 weeks in a classroom under guidance of a classroom teacher.'

Another interview response includes:

'When they get to the schools they enter a conflict situation because many schools do not necessarily agree with how teachers are trained currently, they don't subscribe to the philosophy we're using. So now these students are in a conflict. That's the one side of the story. The other side of the story is when they are with us at the university, we as different subject discipline lecturers also don't communicate with one another as to what the shared expectation is. So teaching practice is a very 
generalised thing as the emphasis is on file this lesson there, plan a sport activity and reflect.'

Another participant indicated:

'Students are generally much better behaved than in the past. They are very helpful and their overall teaching behaviour is good. However, they refuse to get involved in extra-mural activities because they are not checked by university lecturers as there is nothing in it for them. Schools typically want them to become involved in these activities. Students are sent by universities to schools to observe but because they aren't evaluated they are bored by these observations and don't really participate actively in school activities or learn from expert teachers.'

Another participant specified:

'I think it would help a lot because we don't know how much the university is told about the new curriculum. We are in the middle. So if the Education Department did come in and speak to us and to the universities then I think there would be more coherence between the different parties.'

One focus group indicated:

'There is a discrepancy in terms of what the local district requires and what is being told at university what files should look like; how assessment should be done; recording and reporting of assessments. Districts should play a greater role in training especially regarding what they expect of teachers.'

The following examples of extracts from the documents indicate the roles of the schools and the university as well as the format and structure of the WIL experience (see box 3 ).

The results seem to indicate that there is no formal arrangement with schools or teachers, and the WIL period depends, to a large extent, on the goodwill of schools and teachers who assist the students. From the results it is also clear that the roles and responsibilities are very general, and lack scientific depth and rigour in terms of what key partners in the education system should actually be doing and accepting responsibility for. There is also a definite absence of the involvement of partners at, for example, a district level. At this level, one would expect some input from curriculum or subject advisors.

Box 3: An extract from a university indicating the roles of the school and the university for WIL.

1.2 The school
- provides access and exposure to a variety of school contexts;
- appreciates and nurtures the partnership with as provider of teachers in
order to help ensure a high standard of teacher training;
- provides feedback to through mutual communication on the strengths and
weaknesses and possible areas for improvement in the teacher training
programmes.
1.3 The University
- maintains a professional relationship with the schools involved in practice
teaching;
- is involved in developing a system of mentors and in facilitating training and
developmental opportunities;
ensures quality assurance with regard to your training.

\section{The training of teachers to support the pre-service teachers}

Mentoring is integral practice for WIL. The following extracts illustrate how mentors are used in WIL.

\section{An interview participant indicated:}

In this time students spend a minimum of 2 weeks in a classroom under guidance of a classroom teacher.

Another participant stated:

They will learn more from the teacher teaching than they will actually from theory, so the practical experiences are what count a lot.

\section{A focus group interview indicated:}

Yes, we are asked by the University to accommodate them; so then they come to our school, But they don't give us any guidelines as to what the objectives are for the students stay, besides the fact that the students have to, they themselves will say 'I have to teach so-many lessons'. That's all that we actually are informed about so we don't know what else they must learn and do.

The results relevant to this section indicate that no support, in the form of training for teachers involved with WIL at school, takes place. Teachers are merely provided with a general outline of what they should do with the students (e.g. check their lesson planning and presentation; give a mark and give them a few 'tips'). Students also receive very limited support during this period. They have to go out and present lessons and that is it; there is no support in terms of how to conduct themselves (i.e. professional ethos), how to communicate with learners or any reading literacy-specific support (e.g. what if a learner just doesn't get this lesson phonemic awareness?).

Considering the conceptual framework of the study and the evidence of the data, the following aspects can be highlighted. The discussion of the themes which emanated from the data analysis indicates a disconnection among key stakeholders involved in WIL. This highlights the absence of partnerships illustrated in the analysis of the data as well as the literature consulted and compromises the development of effective teachers. This has major implications for the incorporation of WIL into the reading literacy component of teacher preparation programmes. Teacher preparation programmes will have to take a different stance when looking at how WIL is incorporated into their reading literacy component. WIL will have to be 'flipped on its head' or, as Ball and Forzani (2009:497) state, fundamentally renovate WIL in order to be incorporated into the reading literacy component of teacher preparation programmes effectively. The analysis of the data as well as the review of literature indicated that the establishment of collaborative partnerships is imperative. The data explicitly indicated that some form of intervention is needed especially between the schools and universities. 


\section{Conclusion}

Teacher preparation programmes should use WIL as a tool to integrate theory and practice. However, the data suggest that the successful utilisation of this tool for this particular purpose has not been attained. Students are trained to become reading literacy teachers by being exposed to theory within the university classrooms and then they go out to schools for WIL and apply this theory learnt in school classrooms. However, because of the current nature of WIL, fragmentation occurs in the reading literacy component of teacher preparation programmes, and thus the perennial issue of the theory and practice divide persists. This is because there are seldom clear objectives for WIL or how it should link back to the university classroom and student learning. Furthermore, stakeholders involved in WIL are also not always clear of what their role is and how they should contribute to student learning.

The implication of the results of the study will affect all the stakeholders involved in WIL and in the reading literacy component of foundation phase teacher preparation programmes. A process of intervention and reflection should be considered so that WIL can be implemented within the reading literacy component of teacher preparation programmes to bridge the theory and practice divide effectively. The findings of this study support the fundamental renovation of the WIL curriculum of reading literacy teacher preparation programmes. A catalyst in this process is to establish collaborative partnerships among the stakeholders for WIL.

\section{Acknowledgements Competing interests}

The authors declare that they have no financial or personal relationships which may have inappropriately influenced them in writing this article.

\section{Authors' contributions}

C.N. was the project leader for the project (Developing scientific evidence-based knowledge and practice standards for teacher preparation programmes: A focus on literacy and numeracy in English, Setswana and Afrikaans. European Union Primary Education Sector Policy Support programme: Strengthening Foundation Phase Teacher Education) as well as the $\mathrm{PhD}$ supervisor of Z.B. who was a PhD student within this project. Z.B. wrote the article under the guidance and supervision of C.N.

\section{Funding}

This study is based on work sponsored by the National Research Foundation (NRF) of South Africa (UNIQUE Grant No: 92693) and the North-West University (NWU). Any opinions, findings, conclusions or recommendations expressed in this study are those of the authors and do not necessarily reflect the views of the sponsors. The financial assistance of the NRF and NWU is acknowledged with appreciation.

\section{References}

Allington, R., 2002, 'What I've learned about effective teaching instruction from a decade of studying exemplary elementary classroom teachers', Phi Delta Kappan $83(10), 740-747$.

Ambrosetti, A. \& Dekkers, J., 2010, 'The interconnectedness of the roles of mentors and mentees in pre-service teacher education mentoring relationships', Australian Journal of Teacher Education 35(6), 42-55. https://doi.org/10.14221/ajte. $2010 v 35 n 6.3$

Andrew, M.D., 1990, 'Differences between graduates of 4-year and 5-year teacher preparation programs', Journal of Teacher Education 41(2), 45-51.

Ball, D.L. \& Forzani, F.M., 2009, 'The work of teaching and the challenge for teacher education', Journal of Teacher Education 60(5), 497-511.

Boyd, D., Grossman, P., Lankford, H., Loeb, S. \& Wyckoff, J., 2008, Teacher preparation and student achievement, NBER Working Paper Number W14314, National Bureau of Economic Research, Cambridge, MA.

Cantalini-Williams, M., Cooper, L., Grierson, A., Maynes, N., Rich, S., Tessaro, M.L. et al., 2014, Innovative practicum models in teacher education: The benefits, challenges and implementation implications of peer mentorship, service learning and international practicum experiences. Higher Education Quality Council of and international
Ontario, Toronto.

Clifford, M. \& Miller, S.B., 2007, K-20 partnership: A definition and proof-of-concept, Wisconsin Center on Educational Research, University of Wisconsin-Madison, Madison, WI.

Cochran-Smith, M., 2000, 'The future of teacher education: Framing the questions that matter', Teaching Education 11(1), 13-24.

Cooper, L., Orrell, J. \& Bowden, M., 2010, Work-integrated learning: A guide to effective practice, Routledge, New York.

Council on Higher Education (CHE), 2011, Work-integrated learning: Good practice guide, Higher Education Monitor No. 12, CHE, Pretoria.

Cunningham, A.E., Perry, K.E., Stanovich, K.E. \& Stanovich, P.J., 2004, 'Disciplinary knowledge of K-3 teachers and their knowledge calibration in the domain of early literacy', Annals of Dyslexia 54(1), 139-167.

Darling-Hammond, L., 2006, Powerful teacher education: Lessons from exemplary programs, Jossey-Bass, San Francisco, CA.

Darling-Hammond, L. \& Bransford, J., 2006, Preparing teachers for a changing world, Jossey-Bass, San Francisco, CA

Darling-Hammond, L., Bullmaster, M.L. \& Cobb, V.L., 1995, 'Rethinking teacher leadership through professional development schools', The Elementary School Journal 96(1), 87-106.

Department of Basic Education (DBE), 2015, Action plan to 2019. Towards the realisation of schooling 2030, Government Printing Works, Pretoria.

Department of Basic Education (DBE), 2013, Strategy for teaching English across the curriculum, Government Printing Works, Pretoria.

Department of Basic Education (DBE) \& Department of Higher Education and Training (DHET), 2011, Integrated strategic planning framework for teacher education: 2011-2025, Government Printing Works, Pretoria.

Department of Higher Education and Training (DHET), 2011, The minimum requirements for teacher education qualifications, Government Gazette Vol. 583 , No. 34467.

DuFour, R., 2004, 'Leading edge: The best staff development is in the workplace, not in a workshop', Journal of Staff Development 25(2), viewed 24 March 2016, from http://www.nsdc.org/library/publications/jsd/dufour

Glesne, C., 1999, Becoming qualitative researchers: An introduction, Longman, New York.

Gravett, S., Petersen, N. \& Petker, G., 2014, 'Integrating foundation phase teacher education with a "teaching school" at the University of Johannesburg', Education as Change 18(Suppl 1), S107-S119.

Gravett, S., Petersen, N., Ramsaroop, S., Bender, G., Luneta, K., du Plessis, P. et al., 2015, Establishing teaching schools in South Africa, Department of Higher Education and Training, University of Johannesburg, Johannesburg.

Grbich, C., 2007, Qualitative data analysis: An introduction, Sage, Thousand Oaks, CA.

Greef, M., 2011, 'Information collection: Interviewing', in A.S. de Vos, H. Strydom, C.B. Fouché \& C.S.L. Delport (eds.), Research at grass roots for the social sciences and human science professions, pp. 341-374. Van Schaik Publishers, Pretoria, South Africa.

Hall, K.M., Draper, R.J., Smith, L.K. \& Bullough, R.V., 2008, 'More than a place to teach: Exploring the perceptions of the roles and responsibilities of mentor teachers', Mentoring and Tutoring: Partnership in Learning 16(3), 328-345. https://doi. org/10.1080/13611260802231708

Hattie, J., 2009, Visible learning: A synthesis of over 800 meta-analyses relating to achievement, Routledge, London.

Heeralal, P.J.H., 2014, 'Mentoring needs of pre-service teachers during teaching practice: A case study at a South African university', Journal of Educational and Social Research 4(1), 511-516.

Hennissen, P., Crasborn, F., Brouwer, N., Korthagen, F. \& Bergen, T., 2011, 'Clarifying pre-service teacher perceptions of mentor teachers' developing use of mentoring pre-service teacher perceptions of mentor teachers' developing use of mentoring
skills', Teaching and Teacher Education 27, 1049-1058. https://doi.org/10.1016/j. tate.2011.03.009 
Hoffman, J.V., Roller, C. \& National Commission on Excellence in Elementary Teacher Preparation for Reading Instruction, 2001, 'The IRA Excellence in Reading Teacher Preparation Commission's Report: Current practices in reading teacher education at the undergraduate level in the United States', in C. Roller (ed.), Learning to teach reading: Setting the research agenda (pp. 32-79), International Reading teach reading: Setting the

Hollins, E.R. \& Torres Guzman, M., 2005, 'Research on preparing teachers for diverse population', in M. Cochran-Smith \& K. Zeichner (eds.), Studying teacher education The report of the AERA Panel on Research and Teacher Education, pp. 477-544, Lawrence Erlbaum, Mahwah, NJ.

Lave, J. \& Wenger, E., 1991, Situated learning legitimate peripheral participation, Cambridge University Press, Cambridge.

Maxwell, J.A., 2005, Qualitative research design: An interactive approach, 2nd ed. Sage, Thousand Oaks, CA

Merriam, S.B., 2009, Qualitative Research: A guide to design and implementation, Wiley, San Francisco, CA.

Mertens, D.M., 1998, Research methods in education and psychology: Integrating diversity with quantitative and qualitative approaches, Sage, Thousand Oaks, CA.

Moats, L.C. \& Foorman, B.R., 2003, 'Measuring teachers' content knowledge of language and reading', Annals of Dyslexia 53(1), 23-45.

National Research Council, 2010, Preparing teachers: Building evidence for sound policy, National Academies Press, Washington, DC.

Nieuwenhuis, J., 2007, 'Qualitative research designs and data gathering techniques', in K. Maree (ed.) First steps in research, pp. 70-92, Van Schaik Publishers, Pretoria, South Africa.
Palys, T., 2008, 'Purposive sampling', in L.M. Given (ed.), The SAGE encyclopaedia of qualitative research methods. Volume 1 and 2, pp. 697-698, Sage, Thousand Oaks, CA.

Ravitch, S. \& Riggan, M., 2012, Reason and rigour how conceptual frameworks guide research, Sage, Thousand Oaks, CA.

Risko, V.J., Roller, C.M., Cummins, C., Bean, R.M., Block, C.C., Anders, P.L. et al., 2008 'A critical analysis of research on reading teacher education', Reading Research Quarterly 43(3), 252-288.

Robinson, M. 2015, Teaching and learning together: The establishment of professional practice schools in South Africa, A research report for the Department of Higher Education and Training, Stellenbosch University, Stellenbosch.

Rusznyak, L. \& Bertram, C., 2015, 'Knowledge and judgement for assessing student teaching: A cross-institutional analysis of teaching practicum assessment instruments', Journal of Education 60, 31-58.

Shulman, L.S., 1987, 'Knowledge and teaching: Foundations of the new reform', Harvard Educational Review 57(1), 1-22.

Taylor, N., 2015, 'How can teaching become more professional?', JET Bulletin February, 1-2.

Taylor, N. \& Mayet, A., 2015, 'A closer look at teacher education', JET Bulletin, February, 2-6.

Valencia, S.W. \& Buly, M.R., 2004, 'Behind test scores: What struggling readers really need', The Reading Teacher 57(6), 520-531.

Zimmerman, L., Howie, S.J. \& Long, C., 2008, 'Despite every good intention: Challenges to the realisation of objectives for South African B Ed Foundation Phase teacher preparation for literacy teaching', in J. Withers (ed.), Teacher Education Research and Development Programme (TEP) Conference 2008, pp. 45-60, Centre for Education Policy Development, Braamfontein. 


\section{Appendix A}

\section{LESSON OBSERVATION FORM 1}

GRADE

SUBJECT

TOPIC
DURATION OF LESSON

DATE

TEACHER

1. State the lesson outcomes/objectives.

2. Did the teacher link up with prior/existing knowledge during the introduction of the lesson? If yes, explain how and what knowledge was used.

3. Which teaching method/s was/were used?

4. Explain how the learners participated in the lesson.

5. Which teaching media were used? Explain what the teacher used the media for.

6. How did the teacher conclude the lesson?

7. How much time did the teacher approximately spend on the following parts of the lesson:

Introduction minutes

Development minutes

Conclusion minutes

8. Explain how the teacher summarized the lesson. (E.g. by repeating the main points on the writing board, on transparency, by questioning the learners, etc.)

9. Were the learners given work to do in class or at home, or both? Explain what the learners had to do in each case.

Class:

Home:

10. Did the teacher ask the learners any questions?

10.1. Yes / No

10.2. Give an example of a question that was asked and comment on how the learners answered the questions?

10.3. Describe the way in which the teacher reacted to the answers.

Correct answers:

Incorrect answers:

11. How did the teacher keep on course / remember the sequence of what had to be taught in the lesson? (e.g. on transparency, checklist with main points, textbook, relying on memory)

12. Discuss the extent to which the lesson was teacher or learner centered.

13.1. What did you learn about teaching from the way this lesson was taught?

13.2. What, if anything, did you learn about the subject? 


\section{Appendix B}

Course:

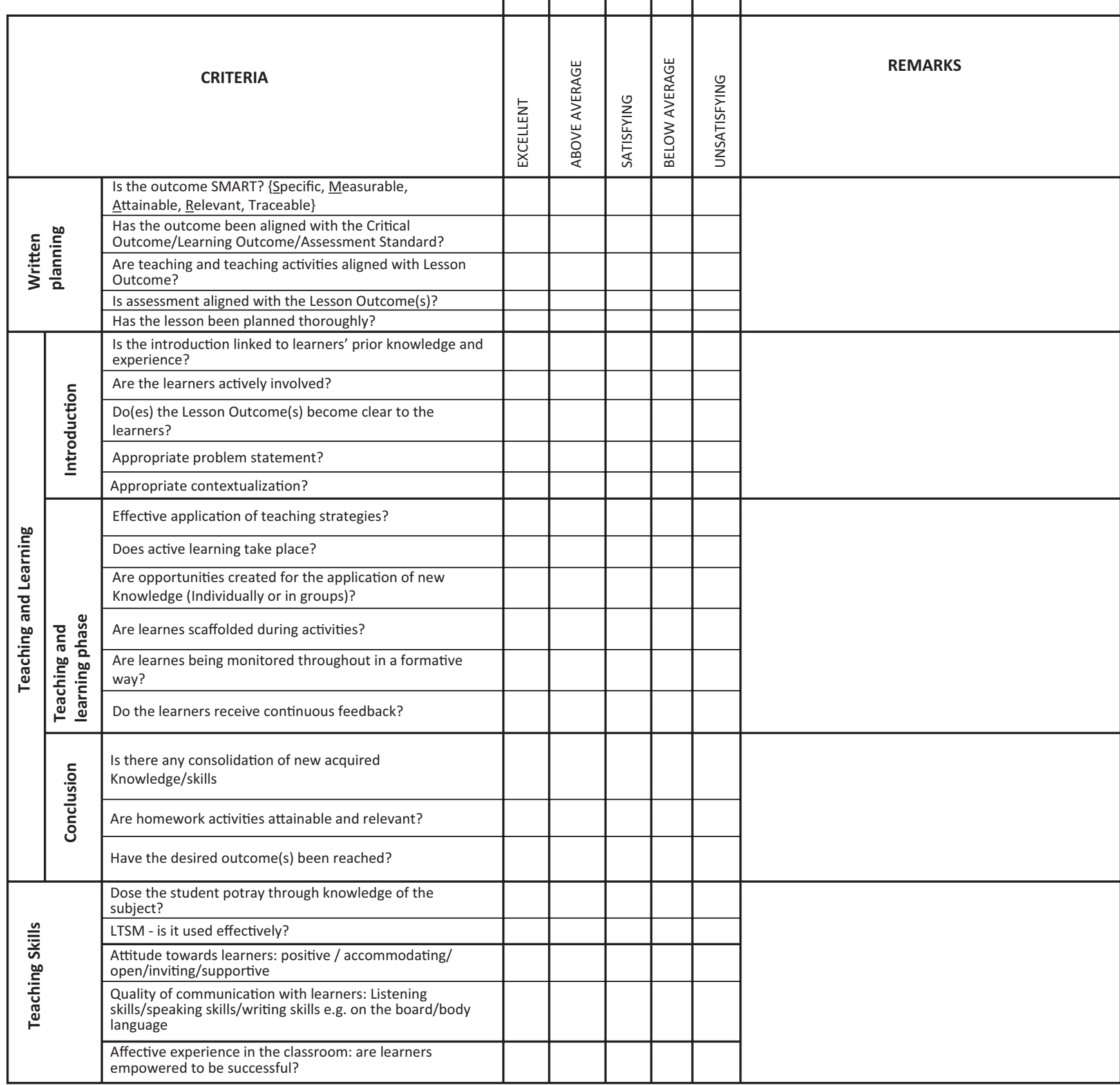

Remarks:

Symbol achieved for lesson:

$A=80 \%$ and above; $B=70 \%-79 \% ; C=60 \% ; D=50 \%-59 \% ; E=0 \%-49 \%$ REPEAT LESSON; 